DOI: $\underline{\text { https://doi.org/10.24867/05FA11Salvai }}$

\title{
PARAMETARSKO MODELOVANJE SOLARNE NADSTREŠNICE PO PRINCIPIMA BIOMIMETIKE
}

\section{PARAMETRIC MODELING OF THE SOLAR CANOPY BASED ON BIOMYMETICS PRINCIPLES}

\author{
Marija Salvai, Fakultet tehničkih nauka, Novi Sad
}

\section{Oblast - DIGITALNE TEHNIKE, DIZAJN I PRODUKCIJA U ARHITEKTURI}

Kratak sadržaj - Korišćenje parametarskog modelovanja kao načina reprezentacije geometrije aktuelna je oblast istraživanja u mnogim inženjerskim naukama. Uz pomoć savremenih tehnologija pružena je mogućnost za otkrivanje novih prirodnih i bioloških sistema, koji se uz pomoć digitalnih tehnologija mogu transformisati $u$ digitalni medijum. Prema tome u okviru istraživanja forme drveta dato je objašnjenje u načinu postizanja iste putem digitalnih alata

Ključne reči: Biomimetika, biomimikrija, bionika, biofilija, biomimetičan dizajn, fraktali

\begin{abstract}
The use of parametric modeling as a way of representing geometry is a current area of research in many engineering sciences. With the help of modern technologies, the opportunity to discover new natural and biological systems has been provided, which can be transformed into digital media with the help of digital technologies. Therefore, within the research of wood form, an explanation was given in how to achieve the same through digital tools.
\end{abstract}

Keywords: Biomimetic, biomimicry, bionics, biophilia, biomimetic design, fractals

\section{UVOD}

Inspiraciju za mnoga dela je čovek uvek tražio u prirodi. Posmatrajući prirodu mnogi naučnici i istraživači su pokušavali da razumeju kako ona funkcioniše. Zahvaljujući sve većem poznavanju sveta koji nas okružuje, ono postaje jednostavnije za širenje granica čovekovih otkrića. Iz tog razloga američki biofizičar Otto Herbert Schmitt je 1957. definisao pojam koji obuhvata ovaj način istraživanja, nazvavši ga Biomimetika. Predmet ovog istraživanja jeste na koje sve načine biomimetički principi mogu imati uticaj prilikom dizajniranja nekog arhitektonskog objekta. U radu će biti istraživana forma drveta kroz vrste digitalnih reprezentacija i uz pomoć kojih alata se ona može dobiti. Cilj istraživanja jeste formiranje geometrije nadstrešnice posredstvom biomimetičkih principa baziranih na logici grananja drveta.

\section{NAPOMENA:}

Ovaj rad proistekao je iz master rada čiji mentor je bio dr Bojan Tepavčević, red. prof.

\section{METODE}

A. Metoda parametarskog modelovanja

Uz pomoć metode parametarskog modelovanja biće prikazano na koje se sve nacine moze dobiti biomimetička forma. Kroz istraživanje primene fraktala i L-sistema $\mathrm{u}$ prirodi, vršiće se poređenje sa sistemom grananja parametarskog modelovanja, uz primenu algoritma.

B. Metoda analize i optimizacije

U radu će biti analizirana solarna radijacija kreirane arhitektonske nadstresnice i na osnovu dobijenih rezultata će biti izvršena optimizacija koja će se ogledati u postavljanju solarnih panela. Kroz algoritam, analiza će pokazati polja sa maksimalnim i minimalnim vrednostima solarne radijacije $\mathrm{i}$ na taj način dati razliku u količini energije koju je moguće dobiti u zavisnosti od položaja solarnih panela.

\subsection{Biomimetika u arhitekturi}

U početnim fazama razvoja arhitekture još od praistorijskih vekova, naši preci su počeli da grade privremene, a kasnije i stalne kuće. Osnonvi cilj je bila zaštita od opasnosti od prirodnih uticaja, poput vremenskih neprilika i divljih životinja. Ovde je veliku ulogu igrala biomimetika, jer su takvi objekti i nastali iz posmatranja i imitiranja prirode, odnosno iz posmatranja na koji način se ostali živi organizmi štite. Na osnovu toga, pored uloge zaštite od opasnosti, kuće su se prilagođavale oblicima u okruženju, pri čemu su korišćeni i materijali iz neposredne blizine. Ovakvi objekti se još mogu pronaći u vernakularnoj arhitekturi, gde su strukture i materijali nadahnuti prirodom [1].

Iako je do danas postignut izuzetan napredak u razvijanju objekata i kuća čije funkcije nisu više samo zaštita od opasnosti, priroda nam još uvek nudi beskonačan niz inovacija koje treba da „,iskopiramo“. Neke osnovne metode i oblici mogu se kopirati, ali ideje prirode najbolje se prilagođavaju ako služe kao uzor ili inspiracija i tako doprinose rafiniranim rezultatima.

Biomimetika, kao što je već spomenuto, predstavlja umetnost i nauku čija je uloga imitiranje prirode radi rešavanja problema današnjice ali i optimizaciju samog života ljudi. Za razliku od Biofilije, čije se učenje bazira na divljenju prirode, Biomimetika proučava strukture na molekularnom nivou, koje egzistiraju u prirodi i na taj način rešava inženjerske probleme. Kao rezultat upotrebe nekih od biomimetičkih principa do sada smo dobili razna naučna i tehnološka rešenja. U prirodi su oduvek postojali zajednički zakoni koji mogu biti primenjivani na životne, 
socijalne i druge organizacione sisteme. Da bi smo iskoristili prednosti ovih zakona, potrebno je proučavati principe prirode za njihovu primenu u organizacijama. To bi predstavljao proces koji je u dizajnu proizvoda $\mathrm{i}$ tehnologije poznat kao kreativni bionički inženjering ili biomimetika [2].

\subsection{Principi Biomimetike u radu}

Biomimetičke principe možemo uopšteno posmatrati na dva načina:

1.) Biološki principi predstavljaju modele za oponašanje, kopiranje i učenje

2.) Biološki principi predstavljaju inspiraciju za nove tehnologije

$\mathrm{U}$ arhitekturi ova dva pristupa mogu biti objašnjena u dva slučaja:

1.) Stvaranje novih, biomimetičkih materijala - ovaj pristup se najviše može uočiti kod konstruisanja novih vrsta materijala koji nastaju upotrebom nanotehnologije

2.) Stvaranje novih metoda $u$ arhitektonskom dizajnu - ovaj model se danas može uočiti u novim pristupima u dizajnu arhitektonskih objekata

Početkom dvadesetog veka Sir D'Arcy Thompson, engleski matematičar i zoolog, bavio se rastom i razvojem oblika. U časopisu '’On Growth and Form'” 1917. godine je opisao da na biološke forme ne utiče samo evolucija, nego i zakoni matematike, fizike i mehanike, koji se ogledaju u matematičkim obrascima struktura. Problem forme je matematički problem, a problem njegovog rasta je, prema Tompsonu, problem fizike [3].

\subsection{Fraktalno drveće}

Za vizuelizaciju I simulaciju rasta biljaka često se koriste algoritmi razvoja kao što su algoritmi L-sistema. Lindermajerovi sistemi su specifična varijanta paralelno prepisivačkog sistema koji se koriste u svrhu modelovanja rasta biljaka u teorijskoj biologiji. Posebno su pogodni za modelovanje rasta geometrije grananja. Simulacija Lsistema se može vršiti uz pomoć dodatka za plugin Grasshopper, koji se naziva Rabbit. Sistem, koji je dobijen u ovom radu, nije rađen uz pomoć Rabbit - a, ali početna faza istraživanja forme je bila bazirana upravo na osnovu ovog dodatka.

\section{PROJEKAT NADSTREŠNICE}

$\mathrm{U}$ narednom delu master rada biće predstavljen projekat nadstrešnice u kojima su primenjeni principi biomimetike. Motiv za projektovanjem ovakvog tipa nadstrešnice $u$ Novom Sadu, koji posebnu pažnju posvećuje razvoju biciklizma i ima izgrađeno više od $65 \mathrm{~km}$ biciklističkih saobraćajnica, proistekao je iz potrebe za punjenjem manjih električnih vozila, posebno bicikala. Kako je bicikli prevozno sredstvo koje ne zagađuje prirodu, bilo ono električno ili manuelno, potrebno je uvek dati podstrek ljudima da koriste ovakav tip prevoza. Vožnja bicikla najviše predstavlja zadovoljstvo kada se vozi kroz prirodne predele u odnosu na gradske urbane sredine, jer je tada čovek više povezan sa prirodom, što ima delotvorne uticaje na ljudski organizam o čemu je već bilo reči u poglavlju Biofilija. Zbog toga je uvek potrebno da arhitekte i dizajneri teže ka projektovanju objekata "proisteklih iz prirode", odnosno nastalih na osnovu biomimetike i da na taj način omogućavaju ljudima da uživaju u gradskim urbanim ' predelima'. Nadstrešnica u ovom radu projektovana je na osnovu tog razmišljanja. Kao rezultat, forma nadstrešnice je nastala iz oblika drveća, i na taj način prikazana kroz biomimetički princip, gde je iz dobijene inspiracije proistekla nova tehnologija, koju u ovom radu možemo nazvati "solarno drveće'.

\subsection{Lokacija}

Lokacija predviđena za izgradnju nadstrešnice je raskrsnica biciklističkih staza na Sunčanom keju. Zona gde se susreću Bulevar cara Lazara i Kej žrtava racije predstavlja intenzivno mesto susreta ljudi u Novom Sadu, koje nema svoj karakterističan izgled kako bi bio reperno definisan. Povodom toga, nadstrešnica "solarno drveće", koja bi bila izgrađena na ovom prostoru definisala bi ga kao repernu tačku $u$ gradu $i$ na taj način olakšalo snalaženje ljudi na ovom mestu susreta.

\subsection{Algoritam}

Za razliku od centroid branching sistema kojim se vodio Yukio Minobe u okviru svoje master teze 'Razgranati ventilacioni omotač', gde on prvobitnom vektoru rasta, koji sačinjava prva grana, dodaje vektor koji je usmeren prema svetlosnom izvoru i tako integriše sledeću granu [4], slika 1, u ovom radu je akcenat stavljen na rotaciji grana oko centralne tačke koja u stvari predstavlja kraj predhodne grane, i na taj način se nastavljaju dalje iteracije.

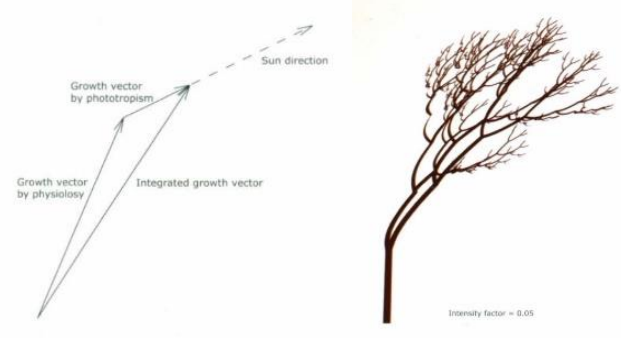

Slika 1. Princip rasta Yukio Minobe [4]

Vodeći se ovim jednostavnim algoritamskim sistemom tačaka, linija, kružnica i rotacija, slika 2, dobijena je forma grananja gde poslednju iteraciju čine 4 grane koje su predviđene da drže jedan poligon/solarni panel, slika 3 .

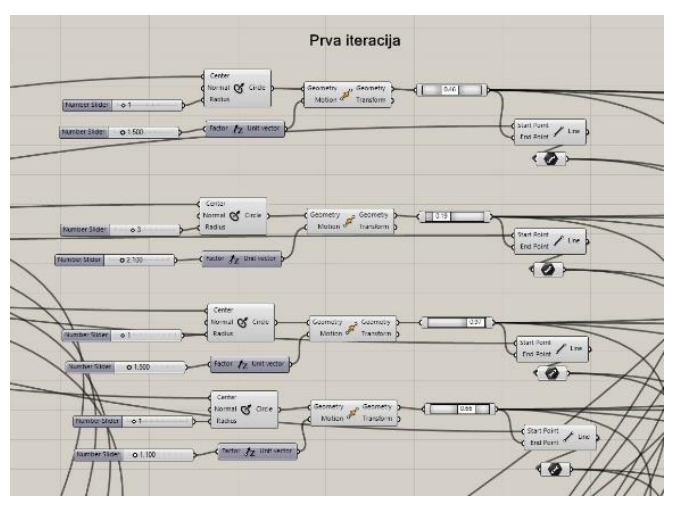

Slika 2. Prikaz algoritma grananja u ovom radu 


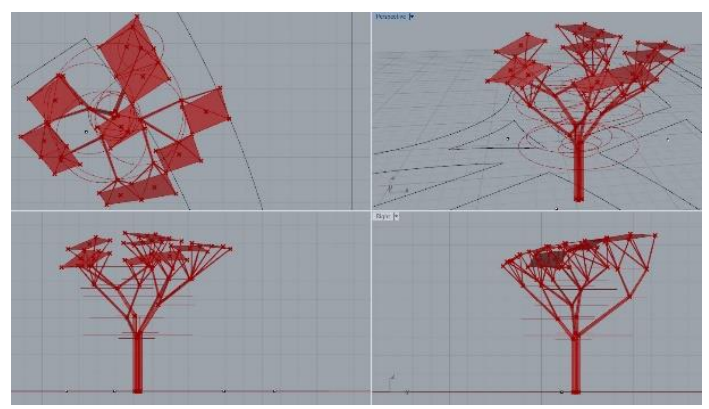

Slika 3. Prikaz algoritma grananja u ovom radu

\subsection{Analiza radijacije i pozicije solarnih panela}

Nakon završene knostrukcije vršena je analiza solarne radijacije u Ladybug dodatku za grasshopper. Radijacija je očitavana na poligonima krova konstrukcije i na osnovu rezultata, koji su pokazali koja polja imaju najveći intenzitet, dobijen je prikaz gde je najoptimalnije postaviti solarne panele. Analiza je rađena u periodu od $24 \mathrm{~h}, 7$. jula 2014. godine, kada je izmeren najtopliji dan u godini. Uz pomoć Ladybug dodatka za Grasshopper je vršen proračun analize, slika 4.

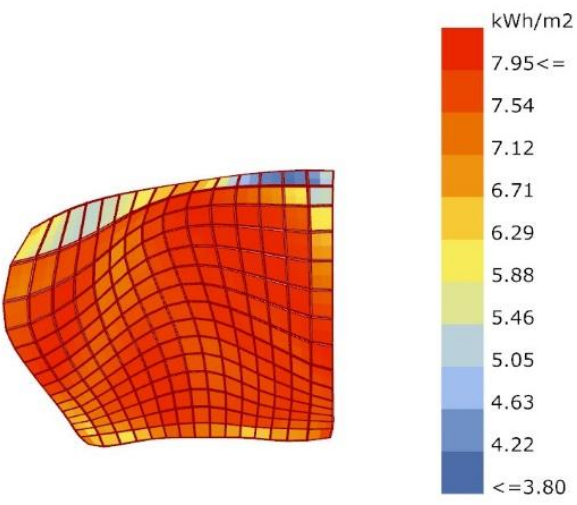

Radiation Analysis

Rotation Angle: 360.0 Degrees

Converted_Podbara_7_7_2014_sa_BG

7 JUL 1:00 - 7 JUL $24: 00$

Slika 4. Analiza solarne radijacije. Na polja koja imaju najveći intenzitet crvene boje su postavljani solarni paneli

Sledeća analiza koja je vršena jeste rotacija celokupne konstrukcije za $360^{\circ}$ oko centralne tačke. Analiza je vršila proračun rotacije na svakih $10^{\circ}$. Analiza je zavisila od pozicije sunca, koji je ovde grafički prikazan uz pomoć Sun-Path diagrama, što predstavlja poziciju sunca na nebu na odgovarajućoj geografskoj širini i visini gde se Novi Sad nalazi. Novi Sad se nalazi na severnoj hemisferi Zemljine polulopte, pa je zbog toga najoptimalnije da solarni paneli budu orijentisani ka jugu.

$\mathrm{Na}$ slici 5 je prikazan rezultat proračuna orijentacije. Analizom je dobijeno da je najoptimalniji ugao rotacije pod $10^{\circ}$ koji iznosi $0.477495 \mathrm{kwh} / \mathrm{m}^{2}$. Medjutim, postojeći ugao rotacije, koji se nalazi pod $0^{\circ}$ ili $360^{\circ}$, iznosi $0.477484 \mathrm{kwh} / \mathrm{m}^{2}$ i prema tome možemo zaključiti da je razlika veoma mala svega $0.000011 \mathrm{kwh} / \mathrm{m}^{2}$. Zbog izuzetno male razlike koja ne bi imala drastično različit uticaj u proizvodnji energije, ovaj podatak možemo zanemariti. Prema tome, nije potrebno raditi promene $u$ konstrukciji.

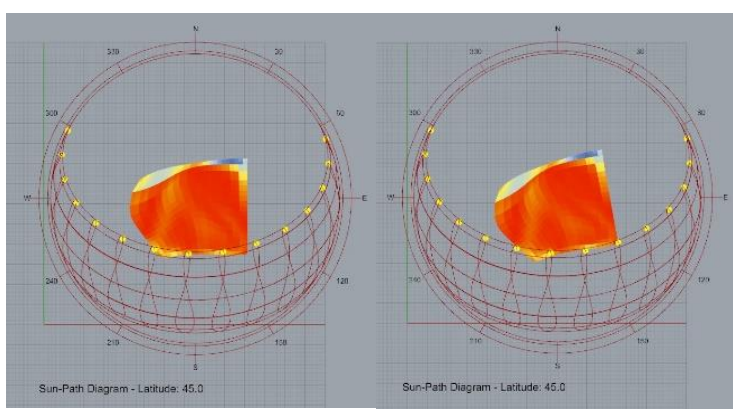

Slika 5. Razlika između orijentacija panela koji daju postojeći dobitak solarne energije (levo) i maksimalni dobitak solarne energije (desno)

\section{VIZUALIZACIJA NADSTREŠNICE}

Vizuelni prikaz parametarski dobijene nadstrešnice dobijen je u programu 3ds Max uz pomoć rendering engine-a Vray render. Geometriju proizvedenu algoritamskim putem moguće je na veoma jednostavan način prevesti u Autodesk-ov program, i na taj način prikazati kako bi ona izgledala u stvarnosti. Da je ovakva vrsta konstrukcije vršena od samog početka u programu kao što je npr. 3ds Max, bilo bi potrebno mnogo više vremena za njenu realizaciju. Prikazi izgleda, osnove i vizuelizacija nadstrešnice prikazani su na slikama $6-10$.

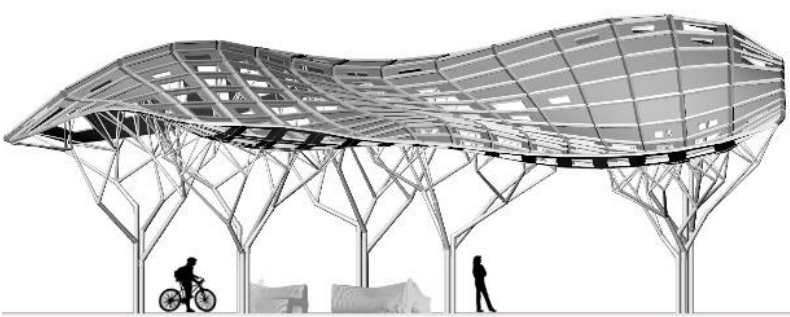

Slika 6. Izgled južni

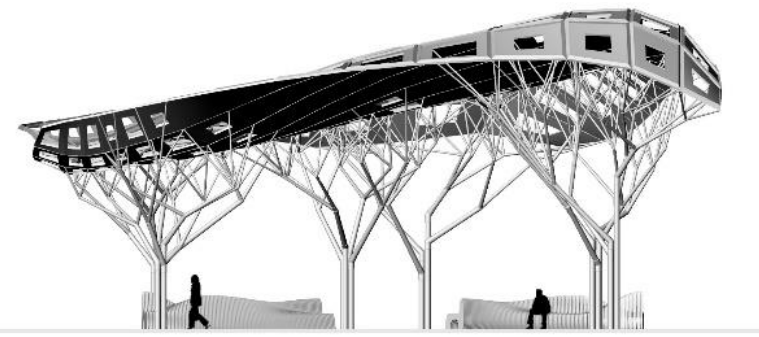

Slika 7. Izgled istočni

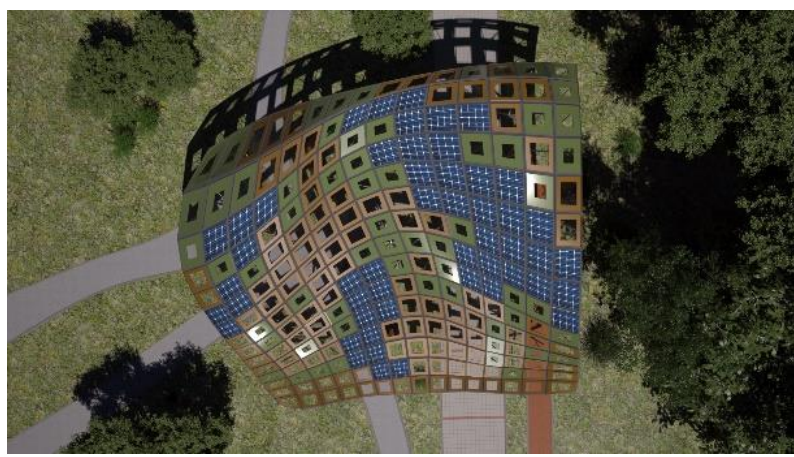

Slika 8. Vizualizacija osnove 


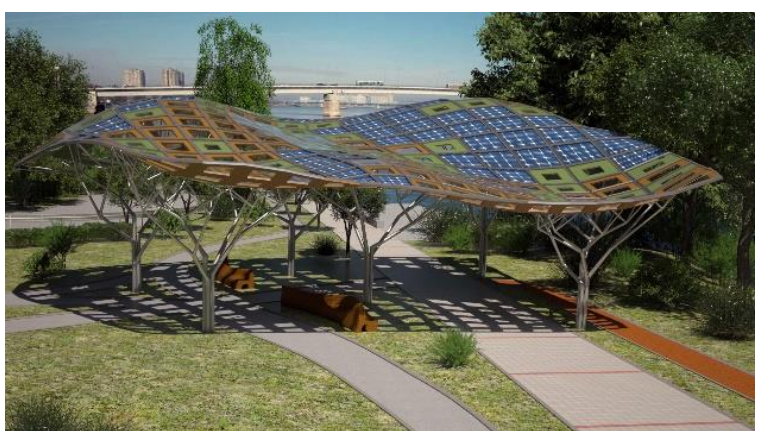

Slika 9. Vizualizacija osnove

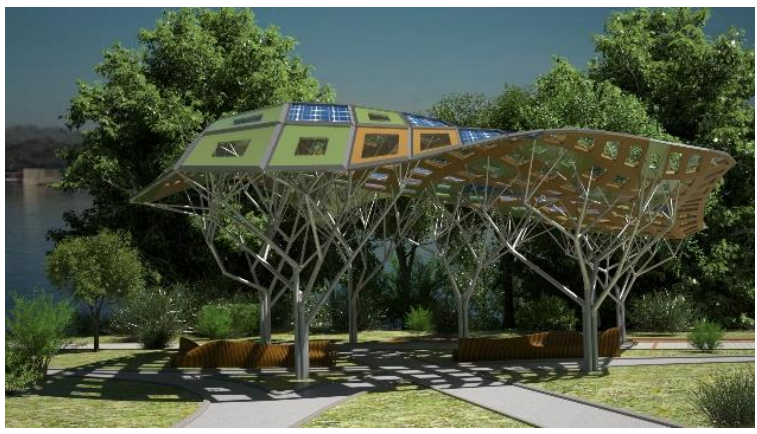

Slika 10. Vizualizacija osnove

\section{ZAKLJUČAK}

$\mathrm{U}$ ovom radu istraživana je biomimetika i njena mogućnost upotrebe kroz biomimetičke principe. Jedan od principa biomimetike, koji je primenjen u ovom radu, a to je princip konstruisanja nove ideje posredstvom bioloških sistema, može se uočiti u jednostavnom pristupu u dizajniranju nadstrešnice. Kao što je sam cilj ovog istraživanja bio formiranje geometrije drveta na osnovu biomimetičkih principa, tako je krajnji rezultat uz pomoć digitalnih tehnika reprezentovan kroz algoritam.

$\mathrm{Na}$ osnovu parametarskog načina modelovanja i uz pomoć dodataka u programima, koji imaju mogućnost da generišu geometriju fraktalnih 1-sistema, ispitane su mogućnosti dolaska do forme drveta. Nakon istraživanja fraktalnih 1-sistema kroz druge naučne radove, doveden je zaključak da je ovaj sistem neodgovarajuć za postizanje željene forme u ovom radu. Fraktalni l-sistemi su u toku pronalaženja forme drveta uglavnom pružali rezultate koji su simetrični i ponavljajući, a takav sistem preslikavanja figura je težio da se izbegne. Obzirom da u prirodi nikada nećemo naići na potpuno simetrične organizme, projektovanje nadstrešnice se vodilo istom logikom. Prema tome, za formiranje razgranate strukture drveta koristila se jednostavna branching metoda $u$ parametarskom modelovanju, jer je ona dala najpribližnije rešenje biomimetičkom modelu drveta.

Krovni deo nadstrešnice, sačinjen od sličnih oblika i različitih dimenzija poligona, imao je za cilj da prikaže mogućnost korišćenja parametarskog modelovanja. Obzirom da svaki poligon poseduje jedinstvenu dimenziju, oni su jednostavno i brzo dobijeni uz pomoć ovog načina modelovanja. Program Grasshopper koji radi po principu parametarskog modelovanja nakon samo nekoliko koraka je generisao površ podelivši je na različite panele. Za ovoliku raznovrsnost dimenzija panela i njihovih otvora, standardnom metodom crtanja bi bilo potrebno mnogo više vremena za njenu realizaciju.
Još jedan primer korišćenja ovog programa jeste mogućnost rada anliza $u$ istom. Zahvaljujući dodatku Ladybug, grasshopper je uspešno izračunao intenzitet solarne radijacije. Dodavanjem samo nekoliko podataka kao što je lokacija područja koji se analizira, u obliku EPW mape i vremenskog perioda, dobijeni su optimalni rezultati položaja solarnih panela.

Rezultati su dali izuzetno malu razliku u proizvodnji energije za različite položaje u odnosu na svetlosni izvor. Prema tome zbog minimalne razlike, nije bilo potrebe za novom adaptacijom konstrukcije. Ova analiza je ujedno služila i za proveru položaja solarnih panela i njihovu produktivnost na odabranoj lokaciji.

$\mathrm{Na}$ osnovu prethodno navedenog možemo zaključiti da je parametarsko modelovanje jedno od važnih načina modelovanja u budućnosti koji zahtevaju brzinu ali i preciznost. Uz pomoć parametarskog modelovanja, pružena je i mogućnost u raznovrsnosti dobijanja forme drveta pa je tako i uz pomoć ove metode dobijen zaključak u ovom radu, gde je korišćenje branching sistema grananja bilo optimalnije rešenje za dobijanje željene forme.

\section{LITERATURA}

[1] Viktoria Sugar, Peter Leczovics, Andras Horkai, "Bionics in architecture", Institute of Architecture, Institute of Civil Engineering, Szent Istvan University, Budapest, Hungary, 2017

[2] Markus Schatten, Miroslav Žugaj, "Biomimetics in modern organizations - Laws or metaphors?",

Faculty of Organization and informatica, University of Zagreb, Croatia, Regular article, 2011.

[3] Martina Zbašnik-Senegačnik, Ljudmila Koprivec, "Biomimetics in the architecture of tomorrow", UL Fakulteta za arhitekturo, 2009.

[4] Michael Hensel, Achim Menges, Michael Weinstock, "Emergent Technologies and Design: towards a biological paradigm for architecture”, Routledge, 2009.

\section{Kratka biografija:}

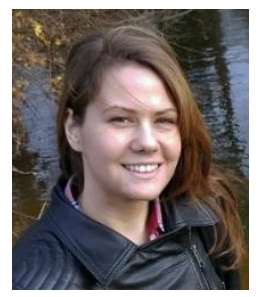

Marija Salvai rođena je u Novom Sadu 1991. Osnove studije završila je u Novom Sadu na Fakultetu Tehničkih nauka, smer arhitektura i urbanizam. Master temu pod nazivom Parametarsko modelovanje nadstrešnice po principima biomimetike iz oblasti arhitekture odbranila je 2019.god. Oblast interesovanja su biomimetički sistemi. 